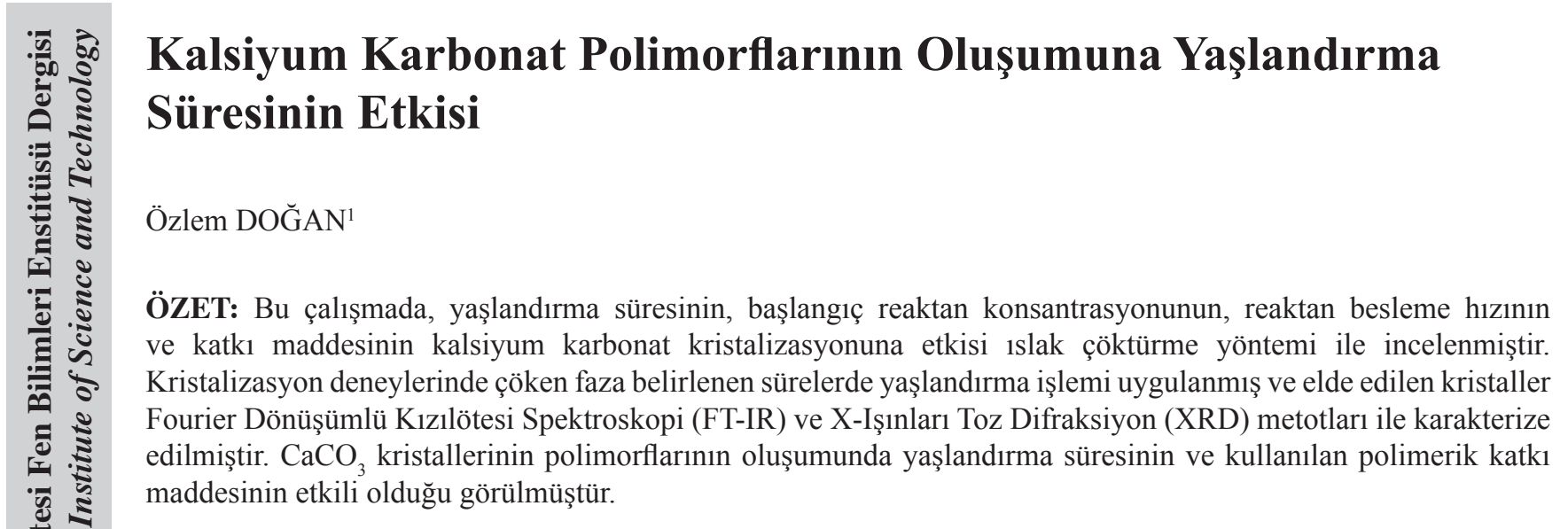

Anahtar Kelimeler: Kalsit, kalsiyum karbonat, kristalizasyon, polimorf, vaterit.

\title{
Effects of Aging Time on The Formation of Calcium Carbonate Polymorphs
}

ABSTRACT: In this work, effects of aging time, initial reactant concentration, reactant feeding rate and a polymeric additive on calcium carbonate crystallization were investigated by wet precipitation. The precipitated phase was aged at specified times. Then the obtained crystal forms were characterized by Fourier Transform Infrared Spectroscopy (FT-IR) and X-Ray Powder Diffraction (XRD) methods. Results showed that the polymorph of the calcium carbonate crystals was affected by aging time and additive used.

Keywords: Calcium carbonate, calcit, crystallization, polymorph, vaterite.

Özlem DOĞAN (0000-0002-1815-7239), Yıldız Teknik Üniversitesi, Kimya Metalurji Fakültesi, Kimya Mühendisliği, İstanbul, Türkiye Sorumlu yazar/Corresponding Author: Özlem DOĞAN, dogano@yildiz.edu.tr 


\section{GíRiş}

İnorganik kristallerin yapısı, büyüklüğü ve morfolojisini kontrol edebilmek, spesifik boyut ve morfolojide malzeme üretimi gerektiren tıp, kataliz, elektronik, seramik pigment ve kozmetik gibi birçok alanda önemlidir. Çekirdek oluşumunu (nükleasyon) ve kristal büyüme prosesini etkileyen termodinamik ve kinetik faktörler çok olmasına rağmen, belirli amaçlar için tasarlanmış ekonomik kristal malzemelerin tekrarlanabilir üretimi son yıllarda en önemli araştırma konularından biri olmuştur. Bu amaçla çözelti pH'1, yaşlandırma süresi değiştirilerek, organik veya inorganik katk1 maddeleri kullanılarak mineral oluşumunun çekirdeklenme ve kristal büyüme aşamalarını kontrol etmek için birçok yaklaşım geliştirilmiştir (Öner et al., 1998; Li et al., 2002; Manoli et al., 2002; Yu et al., 2004; Butler et al., 2006; Kirboga et al., 2016).

Kalsiyum karbonat $\left(\mathrm{CaCO}_{3}\right)$ kristal büyümesi biyolojik, biyokimyasal ve endüstriyel işlemlerde önemlidir. Özellikle polimorflara sahip bir mineral olması ve aşırı doymuş çözeltilerde birden fazla kristal fazı oluşturabilmesi kalsiyum karbonatın önemini arttırmaktadır. Kalsiyum karbonat kalsit, aragonit ve vaterit olmak üzere farklı karakteristik özelliklere sahip üç susuz kristalin polimorfa sahiptir. Termodinamik açıdan en kararlı kristalin yapısı kalsittir. Vaterit ve aragonit termodinamik olarak kararsızdır ve kolaylıkla kalsit haline dönüşebilir. (Xie et al., 2005; Ouhenia et al., 2008; Wang et al., 2009; Chen and Xiang 2009; Hariharan et al., 2014). Kalsiyum karbonat kristalleri genellikle polimorf karışımı ya da bir polimorfun yoğun olduğu karışım şeklinde sentezlenmektedir. Kristal ürünün özellikleri yapısında bulunan polimorfların yüzdesine bağlı olarak değişiklik gösterdiği için, sentezlenmiş kristallerde polimorfların miktarlarının belirlenmesi gerekmektedir. Literatürde farklı polimorf ve morfolojilere sahip $\mathrm{CaCO}_{3}$ kristallerinin sentezi üzerine birçok çalışma bulunmaktadır. $\mathrm{CaCO}_{3}$ kristalizasyonuna katk1 maddesinin (Zhu et al. 2009; Wei et al. 2003), aşırı doygunluğun (Kawano et al. 2002), pH'ın (Han et al. 2006) ve sicaklığın (Gopi et al. 2013) etkisinin incelendiği çalışmalarda çalışma şartlarına bağlı olarak kararsız vaterit fazın kalsit faza dönüşümünün tamamen veya kısmen engellenebildiği görülmüştür. $\mathrm{Bu}$ çalışmada, yaşlandırma süresi, başlangıç reaktan konsantrasyonu, reaktan besleme hızı vekatkımaddesininkalsiyumkarbonatkristalizasyonuna etkisi araştırılmıştır. Katkı maddesi olarak stiren-akrilik kopolimer bazlı sulu mikroemülsiyon kullanılmıştır. FT-IR, XRD analizlerine göre elde edilen $\mathrm{CaCO}_{3}$ kristallerinin polimorfik yapısı yaşlandırma süresine ve katkı maddesi kullanımına bağlı olarak değişiklik göstermiştir.

\section{MATERYAL VE YÖNTEM}

$\mathrm{CaCO}_{3}$ numunelerinin üretimi sslak çöktürme yöntemi ile eşit konsantrasyonda ve eşit hacimde kalsiyum klorür $\left(\mathrm{CaCl}_{2}\right)$ ve sodyum karbonat $\left(\mathrm{Na}_{2} \mathrm{CO}_{3}\right)$ çözeltilerinin $25^{\circ} \mathrm{C}$ 'de karıştırılmasıyla elde edilmiştir. $\mathrm{CaCl}_{2}$ çözeltisi içine $\mathrm{Na}_{2} \mathrm{CO}_{3}$ çözeltisi peristaltik pompa ile beslenmiştir. Ortamdaki $\mathrm{CO}_{2}{ }^{\prime} \mathrm{i}$ uzaklaştırmak için sistemden sürekli azot gazı geçişi sağlanmıştır (Şekil 1). Polimerik katk1 maddesi varlığında gerçekleştirilen deneylerde, polimer $\mathrm{CaCl}_{2}$ ve $\mathrm{Na}_{2} \mathrm{CO}_{3}$ çözeltileri ile birlikte sisteme ilave edilmiştir. İşlem tamamlandıktan sonra çözelti süzülüp elde edilen kristaller saf su ile yıkanmış ve 24 saat boyunca etüvde $100^{\circ} \mathrm{C}$ 'de kurutulmuş ve oda sicaklığında desikatörde saklanmıştır.

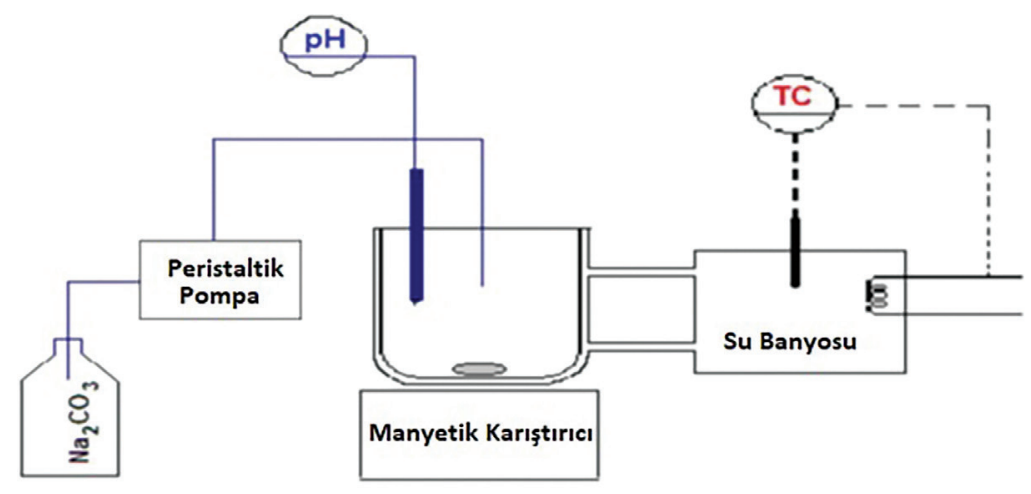

Şekil 1. Deney sistemi. 
Yaşlandırma işlemi uygulanan deneylerde kristaller $25^{\circ} \mathrm{C}$ 'de kendi doygun çözeltisi içinde bekletilmiştir. Yaşlandırma işleminin tamamlanmasından sonra filtre edilerek $100^{\circ} \mathrm{C}^{\prime}$ de kurutulmuş ve oda sıcaklığında desikatörde saklanmıştır.

$\mathrm{CaCO}_{3}$ kristallerinin X-ı̧̧ınları kırınımı (XRD) analizi Panalytical X'Pert Pro cihazı ile $\mathrm{Cu} X$-1şını tüpü $(\lambda=1.5405 \AA)$ kullanılarak $40 \mathrm{~mA}$ ve $45 \mathrm{kV}$ 'de

\section{BULGULAR VE TARTIŞMA}

$\mathrm{CaCO}_{3}$ kristalizasyonuna yaşlandırma süresinin ve polimerik katk1 maddesinin etkisinin incelendiği deneysel çalışmalarda elde edilen kristallerin polimorfik yapıları Çizelge 1'de özetlenmiştir. Kristallerin yapıları $\mathrm{X}$-1şınları ve FT-IR analizleri ile belirlenmiş ve $\mathrm{CaCO}_{3}$ kristalleri olduğu doğrulanmıştır.

$0.1 \mathrm{~mol} \mathrm{~L}^{-1}\left[\mathrm{Ca}^{+2}\right]$ başlangıç konsantrasyonunda, $0.5 \mathrm{~mL} \mathrm{dk}^{-1}$ ve $1 \mathrm{~mL} \mathrm{dk}{ }^{-1} \mathrm{Na}_{2} \mathrm{CO}_{3}$ eklenme hizlarında, farklı yaşlandırma sürelerinde elde edilen $\mathrm{CaCO}_{3}$ kristallerinin FT-IR spektrumları Şekil 2'de verilmiştir. $0.5 \mathrm{~mL} \mathrm{dk}^{-1}$ (C2) ve $1 \mathrm{~mL} \mathrm{dk}^{-1}$ (C4) $\mathrm{Na}_{2} \mathrm{CO}_{3}$ eklenme hızlarında ve yaşlandırma işlemi uygulanmadan elde edilen kristallerin FT-IR spektrumlarında yaklaşık $1450,1085,873$ ve $745 \mathrm{~cm}^{-1}$ civarındaki pikler yapının vaterit olduğunu göstermektedir (Vagenas et al., 2003; Gopi et al., 2013). $1 \mathrm{~mL} \mathrm{dk} \mathrm{dk}^{-1} \mathrm{Na}_{2} \mathrm{CO}_{3}$ eklenme gerçekleştirilmiştir. $2 \theta$ aralığ $5^{\circ}-90^{\circ}$ arasında ölçüm yapılmıştır.

Kristallerin FT-IR analizi Bruker Alpha-P FT-IR Spektroskopisi ile ATR tekniği kullanılarak yapılmıştır. $400-4000 \mathrm{~cm}^{-1}$ dalga boyu aralığında numunelerdeki fonksiyonel grupların adsorbans değerleri belirlenmiş ve elde edilen karakteristik piklerden kalsiyum karbonat kristallerinin yapısı analiz edilmiştir.

hızında ve 1 gün yaşlandırma işlemi uygulanarak elde edilen kristallerin (C5) FT-IR spektrumlarında yine yaklaşık 1450, 1085, 873 ve $745 \mathrm{~cm}^{-1}$ civarındaki görülen pikler yapının vaterit olduğunu göstermektedir (Vagenas et al., 2003; Gopi et al., 2013). $0.5 \mathrm{~mL} \mathrm{dk}^{-1}$ (C3) ve $1 \mathrm{~mL} \mathrm{dk}^{-1}$ (C6) $\mathrm{Na}_{2} \mathrm{CO}_{3}$ eklenme hizlarında ve 7 gün yaşlandırma işleminden sonra elde edilen kristallerin FT-IR spektrumlarında yaklaşık 1400, 872 ve $711 \mathrm{~cm}^{-1}$ civarındaki pikler ise yapının tamamen kalsite dönüştüğünü göstermektedir (Andersen 1991; Shivkumara et al., 2006). $0.1 \mathrm{~mol} \mathrm{~L}^{-1}\left[\mathrm{Ca}^{+2}\right]$ başlangıç konsantrasyonunda elde edilen kristal yapının 0 ve 1 günlük yaşlandırma sürelerinin sonunda vaterit yapıda olduğu ancak 7 günlük yaşlandırma süresinin sonunda kalsit yapıya dönüştüğü görülmektedir. $\mathrm{Na}_{2} \mathrm{CO}_{3}$ eklenme hızının yarıya düşürülmesi polimorfların oluşumunu etkilememiştir.

Çizelge 1. Deneysel parametrelerin $\mathrm{CaCO}_{3}$ kristalizasyonuna etkisi $\left(\mathrm{T}=25^{\circ} \mathrm{C}\right)$.

\begin{tabular}{|c|c|c|c|c|c|}
\hline Deney No & $\begin{array}{c}{\left[\mathrm{Ca}^{+2}\right] \text { ve }\left[\mathrm{CO}_{3}^{-2}\right]} \\
\left(\mathrm{mol} \mathrm{L}^{-1}\right)\end{array}$ & $\begin{array}{c}\mathrm{CO}_{3} \text { Besleme Hızı } \\
\left(\mathrm{mL} \mathrm{dk}^{-1}\right)\end{array}$ & $\begin{array}{c}\text { Polimer } \\
\text { Konsantrasyonu } \\
\left(\mathrm{g} \mathrm{L}^{-1}\right) \\
\end{array}$ & $\begin{array}{l}\text { Yaşlandırma } \\
\text { Süresi } \\
\text { (gün) }\end{array}$ & $\begin{array}{c}\text { Oluşan } \\
\mathrm{CaCO}_{3} \text { Polimorfları }\end{array}$ \\
\hline $\mathrm{C} 1$ & 0.05 & 1 & - & 7 & Kalsit \\
\hline $\mathrm{C} 2$ & 0.1 & 0.5 & - & 0 & Vaterit \\
\hline $\mathrm{C} 3$ & 0.1 & 0.5 & - & 7 & Kalsit \\
\hline $\mathrm{C} 4$ & 0.1 & 1 & - & 0 & Vaterit \\
\hline C5 & 0.1 & 1 & - & 1 & Vaterit \\
\hline C6 & 0.1 & 1 & - & 7 & Kalsit \\
\hline C7 & 0.2 & 0.5 & - & 0 & Vaterit \\
\hline C8 & 0.2 & 0.5 & - & 7 & Kalsit \\
\hline C9 & 0.2 & 1 & - & 0 & Vaterit \\
\hline C10 & 0.2 & 1 & - & 1 & $\% 55$ Kalsit + $\% 45$ Vaterit \\
\hline C11 & 0.2 & 1 & - & 7 & Kalsit \\
\hline CP1 & 0.2 & 1 & 1 & 7 & $\% 4$ Kalsit $+\% 96$ Vaterit \\
\hline CP2 & 0.2 & 1 & 1 & 14 & $\% 13$ Kalsit $+\% 87$ Vaterit \\
\hline
\end{tabular}




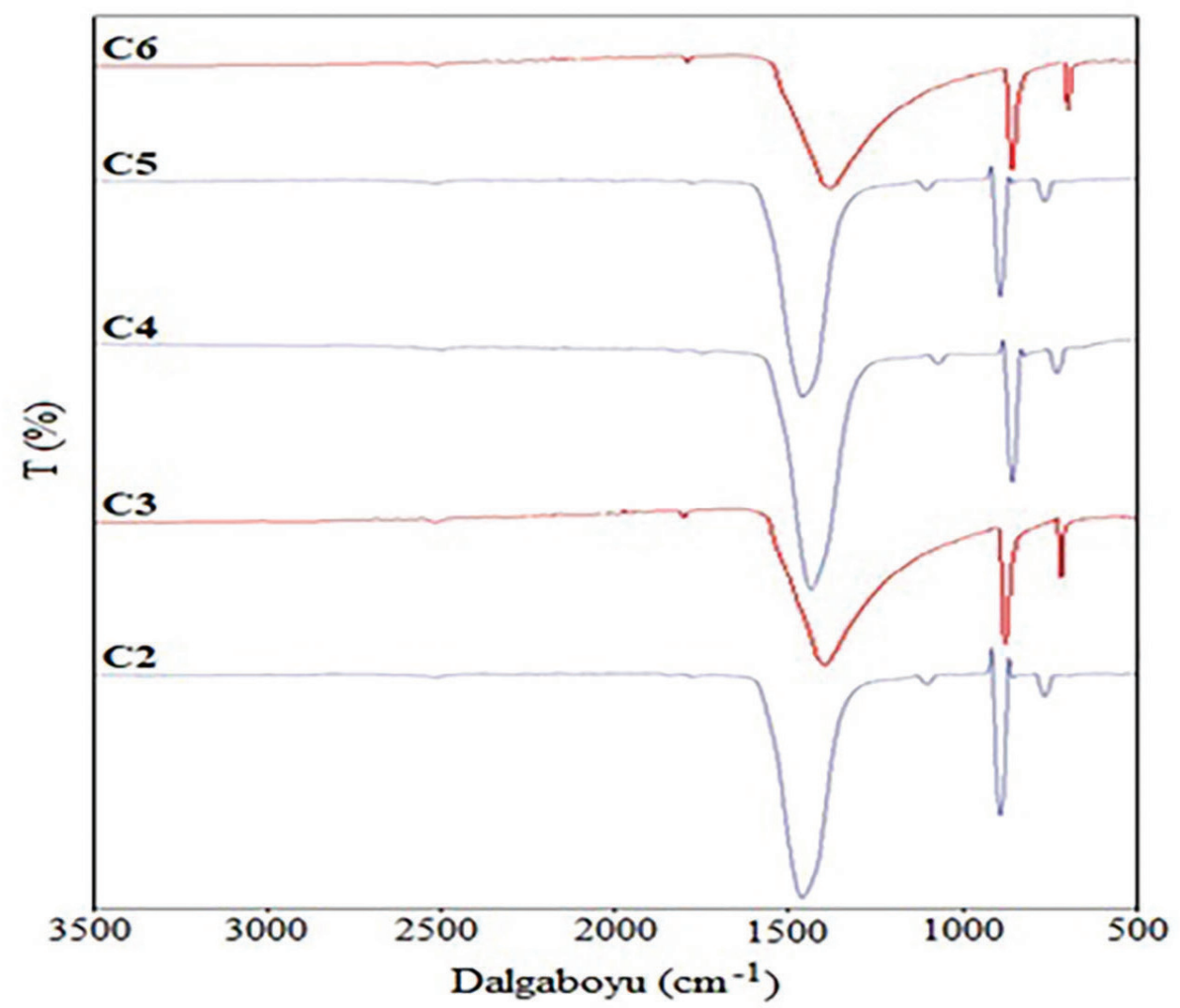

Şekil 2. $\mathrm{CaCO}_{3}$ kristallerinin FT-IR spektrumları $\left(\left[\mathrm{Ca}^{+2}\right]=0.1 \mathrm{~mol} \mathrm{~L}^{-1}\right)$.

$0.2 \mathrm{~mol} \mathrm{~L}^{-1}\left[\mathrm{Ca}^{+2}\right]$ başlangıç konsantrasyonunda,

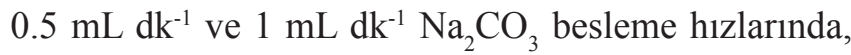
farklı yaşlandırma sürelerinde elde edilen $\mathrm{CaCO}_{3}$ kristallerinin FT-IR spektrumları Şekil 3 'te verilmiştir. $0.5 \mathrm{~mL} \mathrm{dk}^{-1}$ (C7) ve $1 \mathrm{~mL} \mathrm{dk}^{-1}$ (C9) $\mathrm{Na}_{2} \mathrm{CO}_{3}$ besleme hızlarında ve yaşlandırma işlemi uygulanmadan elde edilen kristallerin FT-IR spektrumlarında yaklaşık $1445,1085,873$ ve $745 \mathrm{~cm}^{-1}$ civarındaki pikler yapının vaterit olduğunu göstermektedir (Vagenas et al., 2003;

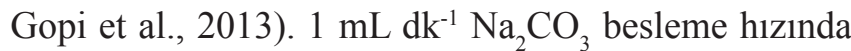
ve 1 gün yaşlandırma işlemi uygulanarak elde edilen kristallerin (C10) FT-IR spektrumları incelendiğinde $1445 \mathrm{~cm}^{-1}$ civarındaki pikin $1440 \mathrm{~cm}^{-1}$ civarına kaydığı ve yaklaşık $710 \mathrm{~cm}^{-1}$ civarında pik oluştuğu görülmektedir. Yaklaşık 1440, 1085, 873, 745 ve 710 $\mathrm{cm}^{-1}$ civarındaki görülen pikler yapının kalsit-vaterit karışımından oluştuğunu göstermektedir (Andersen 1991; Zhang et al., 2012; Gopi et al., 2013). Bu sonuç XRD analiziyle de doğrulanmıştır (Şekil 4). $0.5 \mathrm{~mL} /$ dk (C8) ve $1 \mathrm{~mL} / \mathrm{dk}(\mathrm{C} 11) \mathrm{Na}_{2} \mathrm{CO}_{3}$ besleme hızlarında ve 7 gün yaşlandırma işleminden sonra elde edilen kristallerin FT-IR spektrumlarında yaklaşık 1400, 872 ve $711 \mathrm{~cm}^{-1}$ civarındaki pikler ise yapının tamamen kalsite dönüştügünü göstermektedir (Andersen 1991; Shivkumara et al., 2006). $0.2 \mathrm{~mol} \mathrm{~L}^{-1}\left[\mathrm{Ca}^{+2}\right]$ başlangıç konsantrasyonunda elde edilen kristal yapının 0 günlük yaşlandırma süresi sonunda vaterit yapıda olduğu, 1 günlük yaşlandırma süresi sonunda kalsit-vaterit yapıda olduğu, ancak 7 günlük yaşlandırma süresinin sonunda tamamen kalsit yapıya dönüştüğü görülmektedir. $\mathrm{Na}_{2} \mathrm{CO}_{3}$ eklenme hızının yarıya düşürülmesi polimorfların oluşumunu etkilememiştir. 


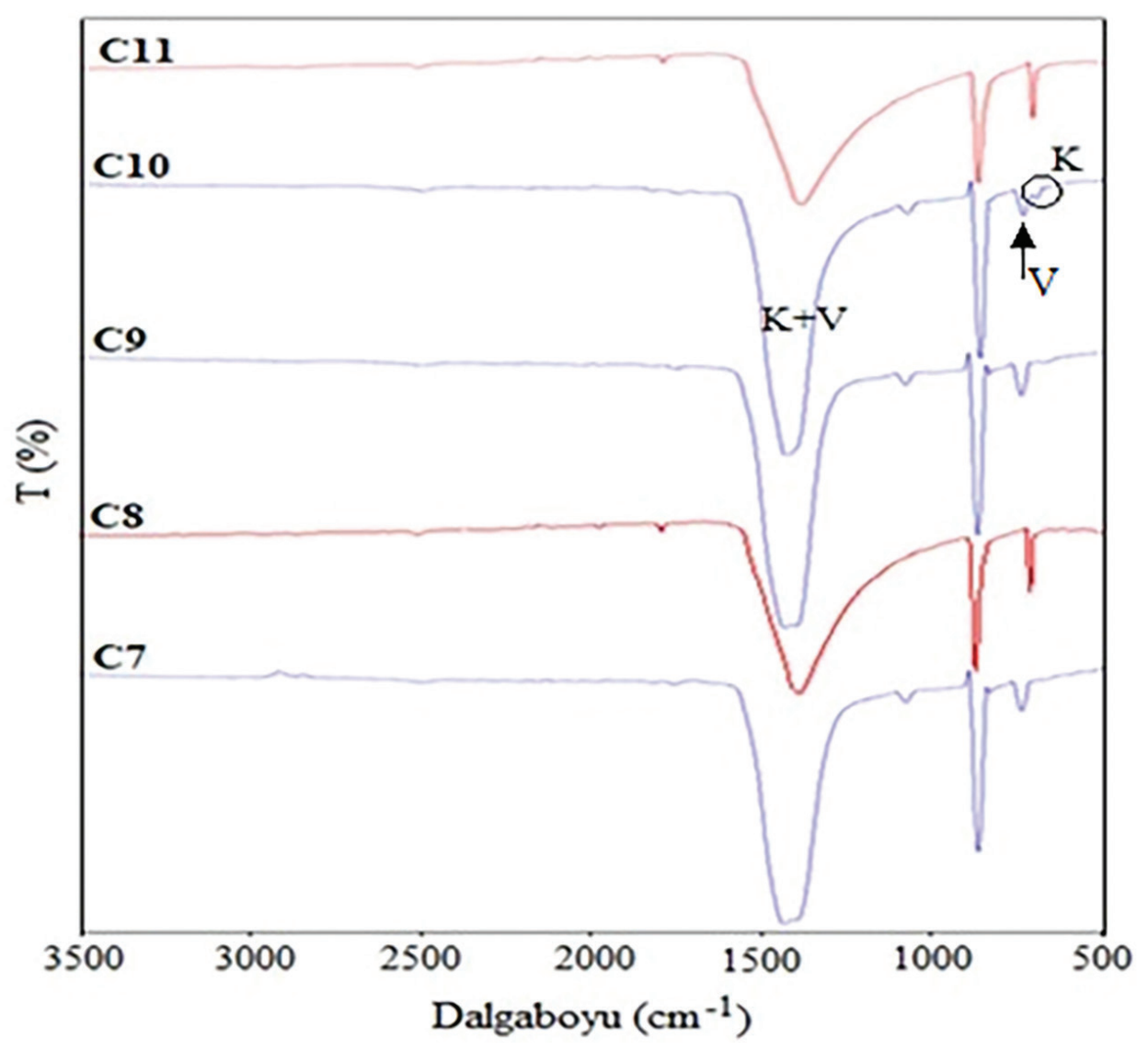

Şekil 3. $\mathrm{CaCO}_{3}$ kristallerinin FT-IR spektrumları $\left(\left[\mathrm{Ca}^{+2}\right]=0.2 \mathrm{~mol} \mathrm{~L}^{-1}\right)$.

$0.2 \mathrm{~mol} \mathrm{~L}^{-1}\left[\mathrm{Ca}^{+2}\right]$ başlangıç konsantrasyonunda, $1 \mathrm{~mL} \mathrm{dk}^{-1} \mathrm{Na}_{2} \mathrm{CO}_{3}$ besleme hızında, farklı yaşlandırma sürelerinde elde edilen $\mathrm{CaCO}_{3}$ kristallerinin XRD analizi sonuçları Çizelge 2 ve Şekil 4 'te verilmiştir. Kristalizasyon deneyleri sonucunda elde edilen ve yaşlandırma işlemi uygulanmayan kristallerin (C9) XRD analizi (JCPDS 01-072-0506) ile vaterit yap1sında olduğu doğrulanmıştır. Vaterit fazına ait karakteristik difraksiyon pikleri, sırasiyla (002), (100), (101), (102), (110), (112), (104) ve (202) miller indislerine karşıll1k gelen $20.9^{\circ}, 24.9^{\circ}, 27.0^{\circ}, 32.7^{\circ}, 43.8^{\circ}, 49.0^{\circ}$, $49.9^{\circ}$ ve $55.7^{\circ} 2 \theta$ değerlerinde görülmektedir. 1 gün yaşlandırma işlemi uygulanan kristallerin (C10) kalsit-vaterit karışımından oluştuğu XRD analizi (JCPDS 01-086-2334 ve JCPDS 00-033-0268) ile doğrulanmıştır. Kalsit fazına ait karakteristik difraksiyon pikleri, sirasiyla (012), (104), (110) ve (202) miller indis- lerine karşıllk gelen $23.0^{\circ}, 29.4^{\circ}, 35.9^{\circ}$ ve $43.1^{\circ} 2 \theta$ değerlerinde görülmektedir.

Vaterit fazına ait karakteristik difraksiyon pikleri ise, sirasiyla (004), (110), (112), (114), (008), (300) ve (118) miller indislerine karş1lı gelen $20.9^{\circ}, 24.9^{\circ}$, $27.0^{\circ}, 32.8^{\circ}, 42.7^{\circ}, 43.8^{\circ}$ ve $50.1^{\circ} 2 \theta$ değerlerinde görülmektedir. 7 gün yaşlandırma işlemi uygulanan kristallerin (C11) ise kalsit yapısında olduğu XRD analizi (JCPDS 01-083-1762) ile doğrulanmıştır. Kalsit fazına ait karakteristik difraksiyon pikleri, sirasiyla (012), (104), (110), (113), (018), (116) ve (122) miller indislerine karş1lık gelen $23.0^{\circ}, 29.4^{\circ}, 35.9^{\circ}, 39.4^{\circ}, 47.5^{\circ}$, $48.5^{\circ}$ ve $57.3^{\circ} 2 \theta$ değerlerinde görülmektedir. Kawano ve ark. (2002) aşırı doygunluğun etkisini incelemişler ve $20^{\circ} \mathrm{C}$ 'de aşırı doygun çözeltiden rombohedral kalsit ve küresel vaterit kristaller sentezlemişlerdir. 
Çizelge 2. C9, C10 ve C11 numunelerinin XRD difraktometre değerleri.

C9 Numunesine ait pikler (Ref. no: 01-072-0506)

\begin{tabular}{ccc}
\hline Int. (\%) & hkl & Faz \\
\hline 11.95 & 002 & $\mathrm{~V}$ \\
77.32 & 100 & $\mathrm{~V}$ \\
100.00 & 101 & $\mathrm{~V}$ \\
84.27 & 102 & $\mathrm{~V}$ \\
54.49 & 110 & $\mathrm{~V}$ \\
13.90 & 112 & $\mathrm{~V}$ \\
39.01 & 104 & $\mathrm{~V}$ \\
12.28 & 202 & $\mathrm{~V}$ \\
\hline
\end{tabular}

C10 Numunesine ait pikler (Ref. no: 00-033-0268 (V) ve 01-086-2334 (K))

\begin{tabular}{ccccc}
\hline $\mathbf{2} \theta$ & $\mathbf{d}(\mathbf{\AA})$ & Int. $(\boldsymbol{\%})$ & hkl & Faz \\
\hline 20.9586 & 4.23520 & 2.16 & 004 & $\mathrm{~V}$ \\
23.0753 & 3.85126 & 2.29 & 012 & $\mathrm{~K}$ \\
24.9042 & 3.57243 & 25.40 & 110 & $\mathrm{~V}$ \\
27.0799 & 3.29014 & 33.24 & 112 & $\mathrm{~V}$ \\
29.4413 & 3.03140 & 100.00 & 104 & $\mathrm{~K}$ \\
32.8398 & 2.72503 & 22.92 & 114 & $\mathrm{~V}$ \\
35.9903 & 2.49339 & 4.69 & 110 & $\mathrm{~K}$ \\
42.7270 & 2.11456 & 2.69 & 008 & $\mathrm{~V}$ \\
43.1854 & 2.09317 & 4.80 & 202 & $\mathrm{~K}$ \\
43.8331 & 2.06373 & 18.96 & 300 & $\mathrm{~V}$ \\
50.1085 & 1.81899 & 12.98 & 118 & $\mathrm{~V}$ \\
\hline
\end{tabular}

\section{C11 Numunesine ait pikler}

(Ref. no: 01-083-1762)

\begin{tabular}{ccccc}
\hline $\mathbf{2 \theta}$ & $\mathbf{d}(\boldsymbol{\AA})$ & Int. $(\boldsymbol{\%})$ & hkl & Faz \\
\hline 23.0610 & 3.85682 & 10.15 & 012 & $\mathrm{~K}$ \\
29.3949 & 3.03859 & 100.00 & 104 & $\mathrm{~K}$ \\
35.9492 & 2.49822 & 13.10 & 110 & $\mathrm{~K}$ \\
39.4042 & 2.28488 & 22.83 & 113 & $\mathrm{~K}$ \\
47.4955 & 1.91279 & 22.56 & 018 & $\mathrm{~K}$ \\
48.4954 & 1.87566 & 22.87 & 116 & $\mathrm{~K}$ \\
57.3842 & 1.60445 & 9.15 & 122 & $\mathrm{~K}$ \\
\hline
\end{tabular}

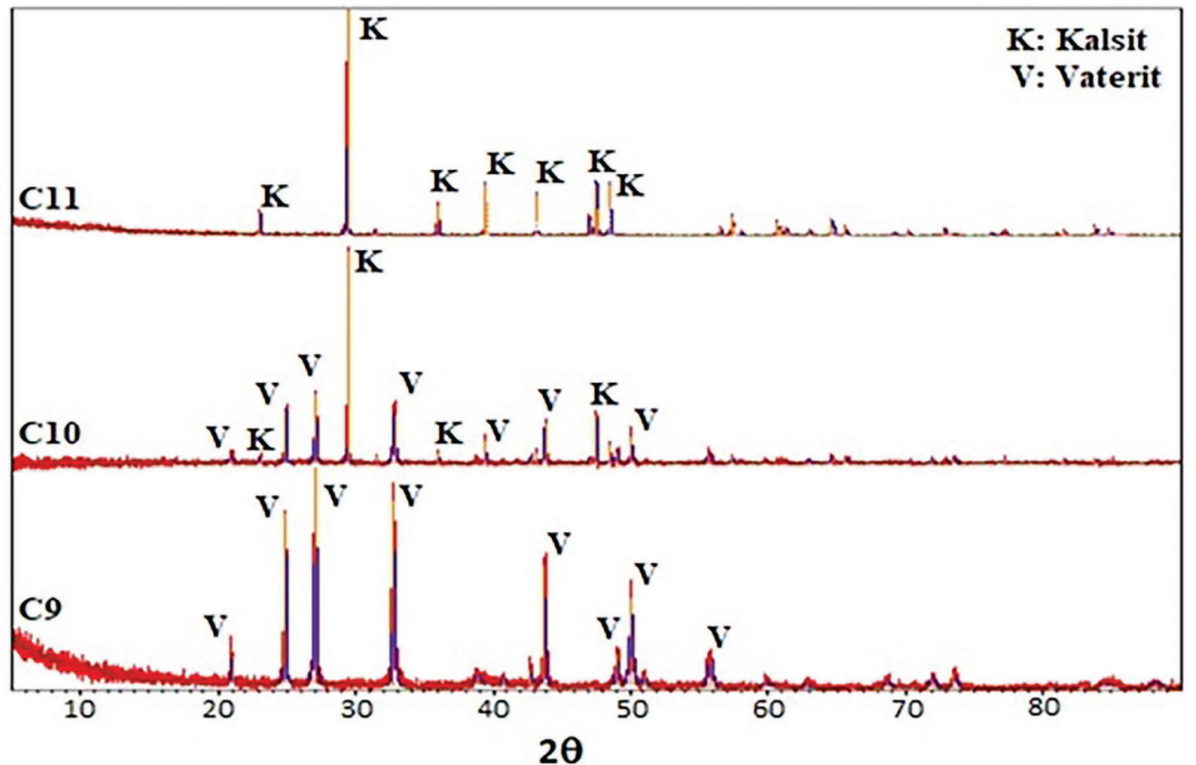

Şekil 4. $\mathrm{CaCO}_{3}$ kristallerinin toz X-ışını difraktometre diyagramı $\left(\left[\mathrm{Ca}^{+2}\right]=0.2 \mathrm{~mol} \mathrm{~L}^{-1}, \mathrm{Na}_{2} \mathrm{CO}_{3}\right.$ besleme hızı=1 $\left.\mathrm{mL} \mathrm{dk}{ }^{-1}\right)$. 
$0.2 \mathrm{~mol} \mathrm{~L}^{-1}\left[\mathrm{Ca}^{+2}\right]$ başlangı̨ç konsantrasyonunda, $1 \mathrm{~mL} \mathrm{dk}^{-1} \mathrm{Na}_{2} \mathrm{CO}_{3}$ besleme hızında, 1 gün yaşlandırma işlemi uygulanan kristallerin $(\mathrm{C} 10)$ yapısındaki vaterit

$$
f_{v}=\frac{I_{v(110)}+I_{v(112)}+I_{v(114)}}{I_{v(110)}+I_{v(112)}+I_{v(114)}+I_{K(104)}}
$$

Burada, $I_{V}$ ve $I_{K}$ sirasiyla XRD difraktometre değerlerinde vaterit ve kalsit fazlarına ait piklerin şiddetini göstermektedir. Çizelge 1'den de görüldüğü gibi aynı şartlarda üretilen ve yaşlandırma işlemi uygulanmayan kristaller (C9) tamamen vaterit yapıda oluşurken, 1 günlük yaşlandırma işlemi sonunda $\% 55$ kalsit ve \%45 vaterit karışımından oluşan kristaller elde edilmiştir. Han ve ark. (2006) kalsiyum karbonat polimorflarının oluşumuna $\mathrm{pH}$ 'ın etkisini inceledikleri çalışmalarında, düşük pH'larda sentezledikleri kristallerin sadece vaterit fazdan oluştuğunu XRD analizi ile göstermişlerdir. Wei ve ark. (2003) fraksiyonu $\left(f_{V}\right)$ Rao's Eşitliği (Eşitlik 1) (Wei et al., 2003; Han et al., 2006) kullanılarak hesaplanmış ve sonuçlar Çizelge 1'de verilmiştir.

termodinamik açıdan kararsız olan vaterit fazın kararlı kalsit faza dönüşümünü poli ( $\mathrm{N}$-vinil-2-pirrolidone) (PVP) varlığında araştırmışlar ve oluşan fazları XRD analizi ile belirlemişlerdir. PVP'nin, vaterit faz oluşumunu engellediğini, kalsit faz oluşumunu ve vaterit fazın kalsit faza dönüşümünü hızlandırdığını bildirmişlerdir.

Farklı başlangıç konsantrasyonlarında, $1 \mathrm{~mL} \mathrm{dk}^{-1}$ $\mathrm{Na}_{2} \mathrm{CO}_{3}$ besleme hızında ve 7 günlük yaşlandırma süresi sonunda elde edilen $\mathrm{CaCO}_{3}$ kristallerinin kalsit yapıda olduğu FT-IR analizi ile doğrulanmıştır (Şekil 5).

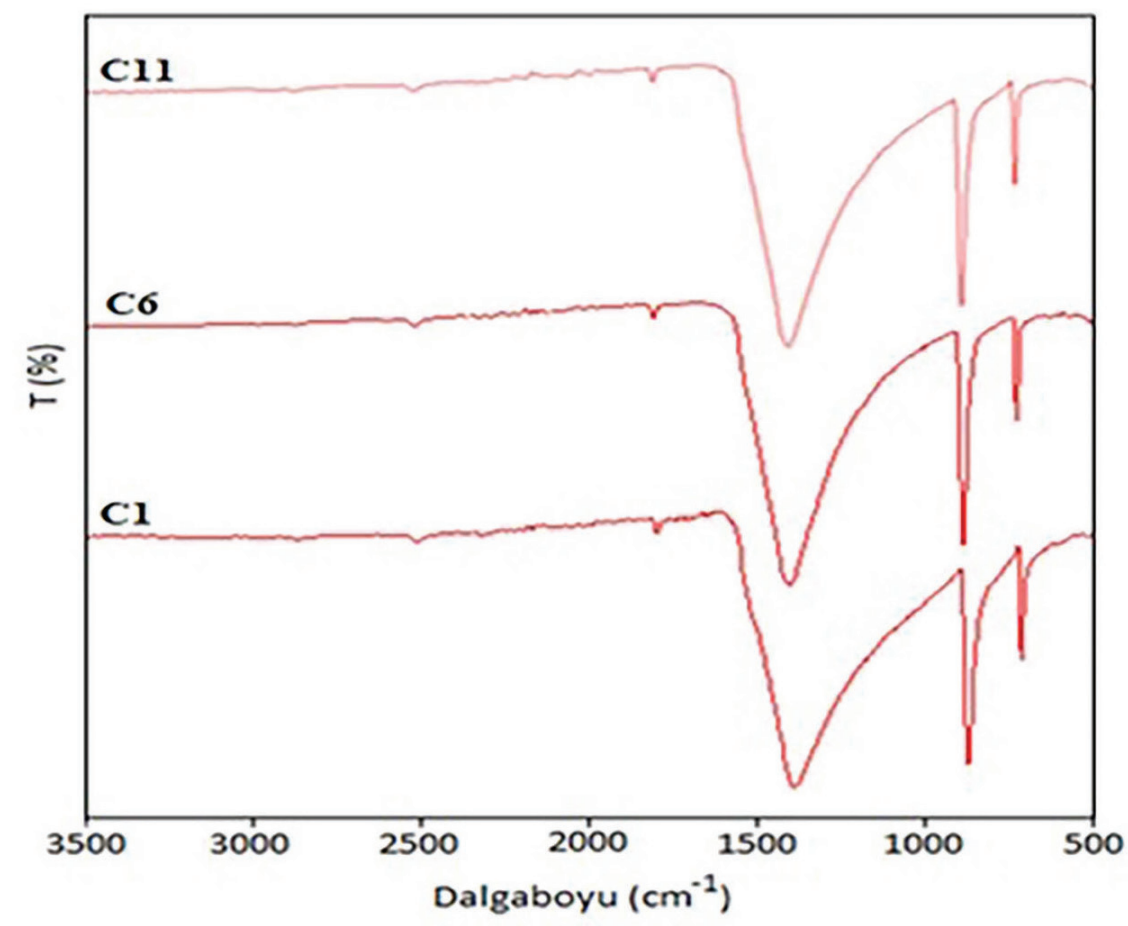

Şekil 5. Farklı başlangıç konsantrasyonlarında elde edilen $\mathrm{CaCO}_{3}$ kristallerinin FT-IR spektrumları $\left(\mathrm{Na}_{2} \mathrm{CO}_{3}\right.$ besleme hızı $=1 \mathrm{~mL}$ dk ${ }^{-1}$, yaşlandırma süresi=7 gün). 
Polimerik katkı maddesinin etkisinin incelendiği kristalizasyon deneyleri $0.2 \mathrm{~mol} \mathrm{~L}^{-1}\left[\mathrm{Ca}^{+2}\right]$ başlangıç konsantrasyonunda, $1 \mathrm{~mL} \quad \mathrm{dk}^{-1} \quad \mathrm{Na}_{2} \mathrm{CO}_{3}$ besleme hızında ve $1 \mathrm{~g} \mathrm{~L}^{-1}$ polimerik katkı maddesi varlığında gerçekleştirilmiştir. Çöken faza 7 ve 14 günlük sürelerde yaşlandırma işlemi uygulanmış ve elde edilen $\mathrm{CaCO}_{3}$ kristallerinin FT-IR analizi sonuçları Şekil 6'da verilmiştir.

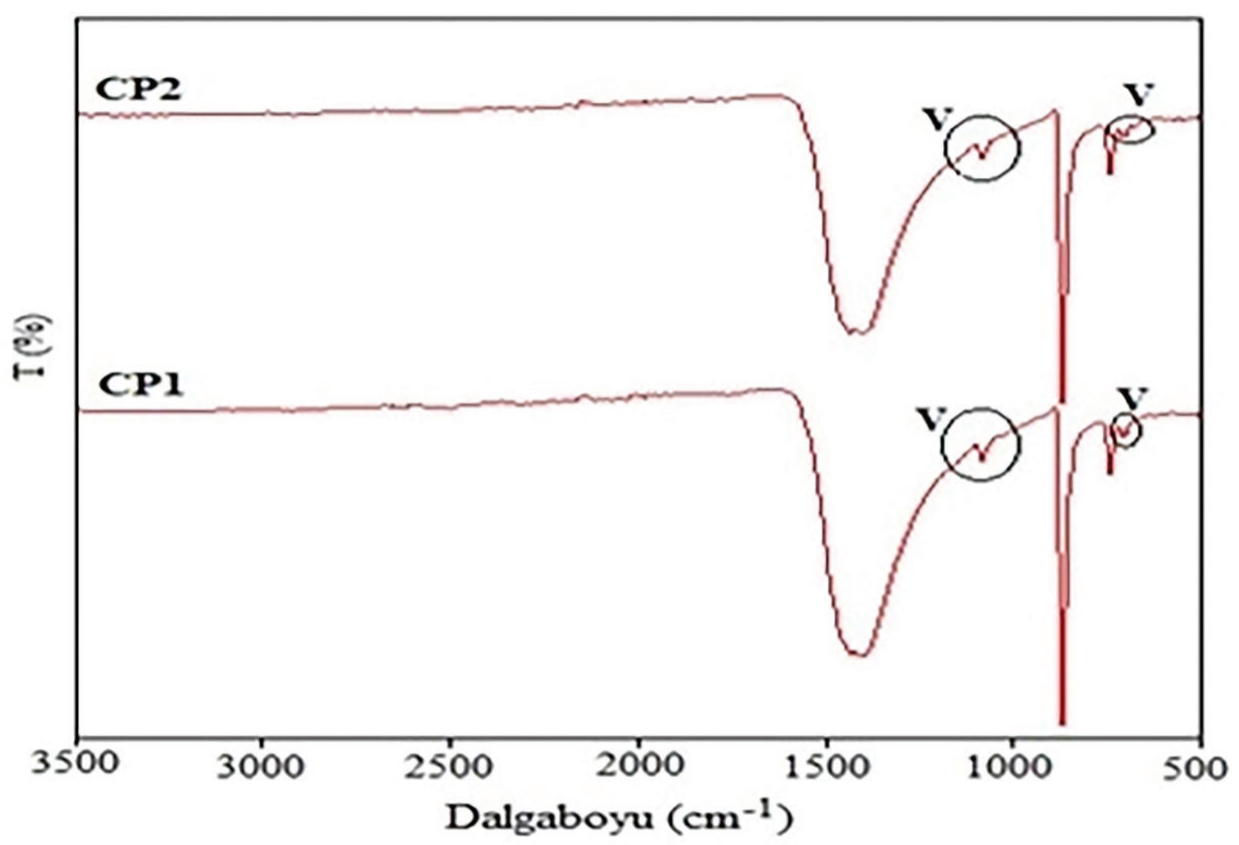

Şekil 6. Polimerik katkı maddesi varlığında elde edilen $\mathrm{CaCO}_{3}$ kristallerinin FT-IR spektrumları $\left(\left[\mathrm{Ca}^{+2}\right]=0.2 \mathrm{~mol} \mathrm{~L}^{-1}, \mathrm{Na}_{2} \mathrm{CO}_{3}\right.$ besleme hızı=1 $\mathrm{mL} \mathrm{dk}^{-1}$, polimer konsantrasyonu $\left.=1 \mathrm{~g} \mathrm{~L}^{-1}\right)$.

FT-IR spekturumları incelendiğinde (CP1 ve CP2) kristallerin tamamen kalsit yapıya dönüşmesi için 7 ve 14 günlük yaşlandırma sürelerinin yeterli olmadığı, kristallerin kalsit-vaterit karışımından oluştuğu görülmektedir. Yaklaşık 1435, 873 ve 712 $\mathrm{cm}^{-1}$ civarında görülen pikler kalsit yapısının, yaklaşı 1088 ve $745 \mathrm{~cm}^{-1}$ civarındaki pikler ise vaterit yapısının varlığını göstermektedir (Andersen 1991).

$1 \mathrm{~g} \mathrm{~L}^{-1}$ polimerik katkı maddesi varlığında elde edilen $\mathrm{CaCO}_{3}$ kristallerinin XRD analizi sonuçları Çizelge 3 ve Şekil 7'de verilmiştir. Şekil 7'den de görüldüğü gibi polimerik katkı maddesi varlığında elde edilen kristaller kalsit-vaterit karışımından oluşmaktadır. 7 gün yaşlandırma işlemi uygulanan kristallerin (CP1) kalsit-vaterit karışımından oluştuğu XRD analizi (JCPDS 01-072-1651 ve JCPDS 00-0330268) ile doğrulanmıştır. Kalsit fazına ait karakteristik difraksiyon piki (104) miller indisine karşılık gelen $29.5^{\circ} 2 \theta$ değerinde görülmektedir. Vaterit fazına ait karakteristik difraksiyon pikleri ise, sirasiyla (004), (110), (112), (114), (008), (300), (304), (118) ve (224) miller indislerine karş1llk gelen $21.0^{\circ}, 24.9^{\circ}$, $27.1^{\circ}, 32.8^{\circ}, 42.8^{\circ}, 43.9^{\circ}, 49.1^{\circ}, 50.1^{\circ}$ ve $55.9^{\circ} 2 \theta$ değerlerinde görülmektedir. 14 gün yaşlandırma işlemi uygulanan kristallerin (CP2) kalsit-vaterit karışımından oluştuğu XRD analizi (JCPDS 01-072-1651 ve JCPDS 00-033-0268) ile doğrulanmıştır.

Kalsit fazına ait karakteristik difraksiyon pikleri, sirasiyla (012), (104), (110) ve (113) miller indislerine karş1lık gelen $23.1^{\circ}, 29.4^{\circ}, 36.0^{\circ}$ ve $39.5^{\circ}$ $2 \theta$ değerlerinde görülmektedir. Vaterit fazına ait karakteristik difraksiyon pikleri ise, sirasiyla (004), (110), (112), (114), (008), (300), (304), (118) ve (224) miller indislerine karşıllık gelen $21.0^{\circ}, 24.9^{\circ}$, $27.1^{\circ}, 32.8^{\circ}, 42.8^{\circ}, 43.9^{\circ}, 49.1^{\circ}, 50.1^{\circ}$ ve $55.9^{\circ} 2 \theta$ değerlerinde görülmektedir. 
Çizelge 3. CP1 ve CP2 numunelerinin XRD difraktometre değerleri.

CP1 Numunesine ait pikler

(Ref. no: 00-033-0268 (V) ve 01-072-1651 (K))

\begin{tabular}{ccccc}
\hline $\mathbf{2 \theta}$ & $\mathbf{d}(\AA)$ & Int. $(\%)$ & hkl & Faz \\
21.0836 & 4.21385 & 14.03 & 004 & $\mathrm{~V}$ \\
24.9983 & 3.56214 & 72.91 & 110 & $\mathrm{~V}$ \\
27.1733 & 3.28176 & 100.00 & 112 & $\mathrm{~V}$ \\
29.5175 & 3.02625 & 8.98 & 104 & $\mathrm{~K}$ \\
32.8877 & 2.72344 & 81.14 & 114 & $\mathrm{~V}$ \\
42.8135 & 2.11223 & 7.09 & 008 & $\mathrm{~V}$ \\
43.9452 & 2.06043 & 59.06 & 300 & $\mathrm{~V}$ \\
49.1797 & 1.85268 & 14.98 & 304 & $\mathrm{~V}$ \\
50.1535 & 1.81897 & 36.50 & 118 & $\mathrm{~V}$ \\
55.9238 & 1.64419 & 12.04 & 224 & $\mathrm{~V}$ \\
\hline
\end{tabular}

CP2 Numunesine ait pikler

(Ref. no: 00-033-0268 (V) ve 01-072-1651 (K))

\begin{tabular}{ccccc}
\hline $\mathbf{2 \theta}$ & $\mathbf{d}(\mathbf{\AA})$ & Int. (\%) & hkl & Faz \\
21.0711 & 4.21633 & 21.95 & 004 & $\mathrm{~V}$ \\
23.1461 & 3.84283 & 2.92 & 012 & $\mathrm{~K}$ \\
24.9891 & 3.56343 & 70.07 & 110 & $\mathrm{~V}$ \\
27.1613 & 3.28319 & 100.00 & 112 & $\mathrm{~V}$ \\
29.4982 & 3.02819 & 36.79 & 104 & $\mathrm{~K}$ \\
32.8657 & 2.72521 & 86.90 & 114 & $\mathrm{~V}$ \\
36.0842 & 2.48918 & 3.73 & 110 & $\mathrm{~K}$ \\
39.5138 & 2.28068 & 10.10 & 113 & $\mathrm{~K}$ \\
42.8262 & 2.11164 & 8.35 & 008 & $\mathrm{~V}$ \\
43.9455 & 2.06042 & 51.27 & 300 & $\mathrm{~V}$ \\
49.1854 & 1.85248 & 13.88 & 304 & $\mathrm{~V}$ \\
50.1686 & 1.81846 & 43.06 & 118 & $\mathrm{~V}$ \\
55.9083 & 1.64461 & 13.38 & 224 & $\mathrm{~V}$ \\
\hline
\end{tabular}

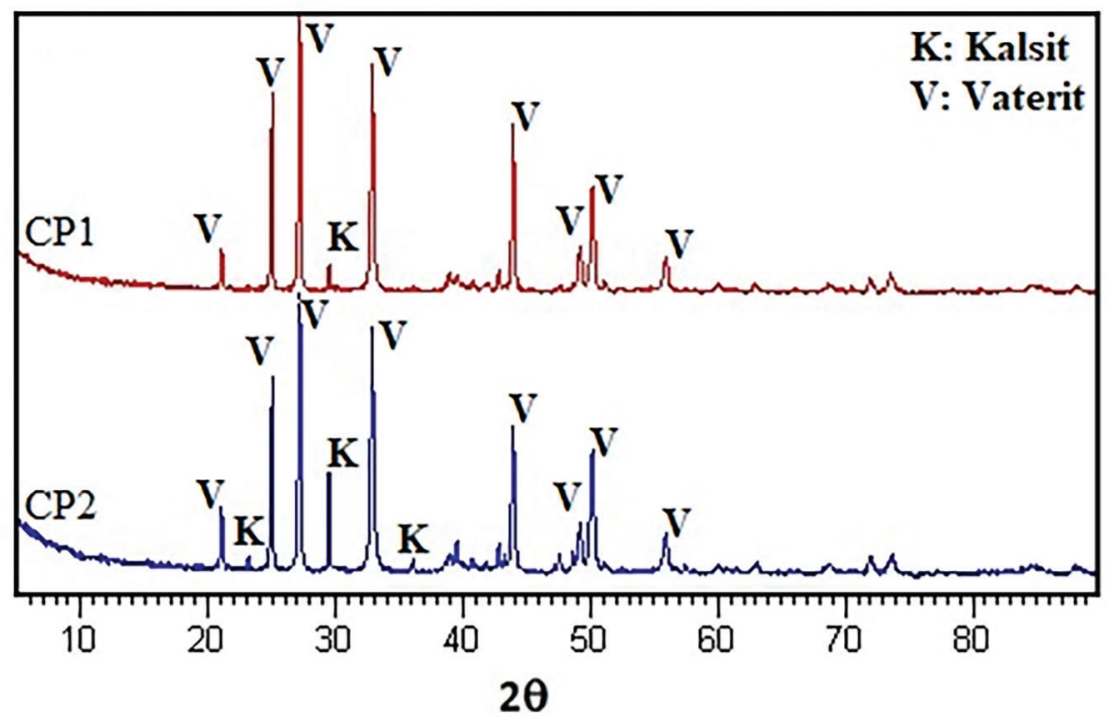

Şekil 7. $\mathrm{CaCO}_{3}$ kristallerinin toz $\mathrm{X}-1$ şını difraktometre diyagramı $\left(\left[\mathrm{Ca}^{+2}\right]=0.2 \mathrm{~mol} \mathrm{~L}^{-1}, \mathrm{Na}_{2} \mathrm{CO}_{3}\right.$ besleme hızı $=1 \mathrm{~mL} \mathrm{dk}^{-1}$, polimer konsantrasyonu $\left.=1 \mathrm{~g} \mathrm{~L}^{-1}\right)$.

Polimer varlığında elde edilen kristallerin yapısındaki vaterit fraksiyonu (Eşitlik 1) kullanılarak hesaplanmış ve sonuçlar Çizelge 1'de verilmiştir. Çizelge 1'den de görüldüğü gibi 7 günlük yaşlandırma işlemi sonunda elde edilen kristaller (CP1) \%4 kalsit ve \%96 vaterit karışımından, oluşurken, 14 günlük yaşlandırma işlemi sonunda elde edilen kristaller (CP2) $\% 13$ kalsit ve \%87 vaterit karışımından oluşmaktadır. Yaşlandırma süresi arttıkça oluşan kristal yapıda vaterit fazın oranı azalmaktadır. Gopi ve ark. (2013) kalsiyum karbonat kristalizasyona sicaklığın ve katkı maddesinin etkisini inceledikleri çalışmalarında, $60^{\circ} \mathrm{C} \% 81$ kalsit - 
$\% 19$ aragonit karışımından oluşan kristaller, $230^{\circ} \mathrm{C}^{\prime} \mathrm{de}$ ise $\% 97$ kalsit - \%3 aragonit karışımından oluşan kristaller elde etmişlerdir. Dietillen triamin penta asetik asit (DTPA) varlığında; $60^{\circ} \mathrm{C} \% 7$ kalsit - \%93 aragonit karışımından oluşan kristaller, $230^{\circ} \mathrm{C}$ 'de ise $\% 2$ kalsit -

\section{SONUÇ}

Yaşlandırma süresi ve polimerik katkı maddesinin $\mathrm{CaCO}_{3}$ kristallerinin polimorflarının oluşumuna etkili olduğu bulunmuştur. Çalışılan $\left[\mathrm{Ca}^{+2}\right]$ başlangıç konsantrasyon ve $\mathrm{Na}_{2} \mathrm{CO}_{3}$ besleme hızı değerlerinde, 1 günlük yaşlandırma süresinin saf $\mathrm{CaCO}_{3}$ numunelerinin kalsite dönüşümü için yeterli olmamıştır. Saf $\mathrm{CaCO}_{3}$ numuneleri 7 günlük yaşlandırma işlemi sonunda

\section{KAYNAKLAR}

Andreassen JP, 2005. Formation mechanism and morphology in precipitation of vaterite-nano-aggregation or crystal growth? J. Crystal Growth, 274: 256-264.

Butler MF, Glaser N, Weaver AC, Kirkland M, Heppenstall-Butler $M, 2006$. Calcium carbonate crystallization in the presence of biopolymers. Crystal Growth\&Design, 6 (3): 781-794.

Chen J, Xiang L, 2009. Controllable synthesis of calcium carbonate polymorphs at different temperatures. Powder Technology, 189: 64-69.

Gopi S, Subramanian VK, Palanisamy K, 2013. Aragonite-calcitevaterite: A temperature influenced sequential polymorphic transformation of $\mathrm{CaCO} 3$ in the presence of DTPA. Materials Research Bulletin 48: 1906-1912.

Han YS, Hadiko G, Fuji M, Takahashi M, 2006. Crystallization and transformation of vaterite at controlled $\mathrm{pH}$. J. Crystal Growth, 289: $269-274$

Hariharan M, Varghese N, Cherian AB, Sreenivasan PV, Paul J, Antony AKA, 2014. Synthesis and characterisation of $\mathrm{CaCO}_{3}$ (calcite) nano particles from cockle shells using chitosan as precursor. International Journal of Scientific and Research Publications, 4 (10): 1-5.

Kawano J, Shimobayashi N, Kitamura M, Shinoda K, Aikawa N, 2002. Formation process of calcium carbonate from highly supersaturated solution, J.Crystal Growth, 237-239: 419-423.

Kirboga S, Öner M, Dogan Ö, 2016. Box-Behnken experimental design for the production of precipitated calcium carbonate. Pure Appl. Chem., 88(10-11): 961-968.

Li C, Botsaris GD, Kaplan DL, 2002. Selective in vitro effect of peptides on calcium carbonate crystallization. Crystal Growth\&Design, 2 (5): 387-393.

Manoli F, Kanakis J, Malkaj P, Dalas E, 2002. The effect of aminoacids on the crystal growth of calcium carbonate. J. Crystal Growth, 236: 363-370.
$\% 8$ aragonit - $\% 90$ vaterit karışımından oluşan kristaller elde etmişlerdir. Katkı maddesinin varlığının kararsız vaterit fazın oluşumunu sağladığını belirtmişlerdir (Gopi et al., 2013).

tamamen kalsite yapıya dönüşürken, polimer katkılı üretilen $\mathrm{CaCO}_{3}$ numuneleri 14 günlük yaşlandırma işlemi sonunda $\% 13$ kalsit ve $\% 87$ vaterit karışımından oluştuğu görülmüştür. Bu çalışmada, aşırı doygunluk, yaşlandırma süresi, katkı maddesi ve karıştırma hızı gibi deneysel şartların değiştirilerek kullanım alanına uygun istenilen özelliklere sahip kalsiyum karbonat polimorflarının sentezlenebileceği gösterilmiştir.

Ouhenia S, Chateigner D, Belkhir MA, Guilmeau E, Krauss C, 2008. Synthesis of calcium carbonate polymorphs in the presence of polyacrylic acid. J. Crystal Growth, 310: 2832-2841.

Öner M, Dogan Ö, Öner G, 1998. The Influence of polyelectrolytes architecture on calcium sulfate dihydrate growth retardation. J.Crystal Growth, 186 (3), 427-437.

Shivkumara C, Singh P, Gupta A, Hegde MS, 2006. Synthesis of vaterite $\mathrm{CaCO} 3$ by direct precipitation using glycine and L-alanine as directing agents. Materials Research Bulletin, 41: $1455-1460$

Vagenas NV, Gatsouli A, Kontoyannis CG, 2003. Quantitative analysis of synthetic calcium carbonate polymorphs using FTIR spectroscopy. Talanta, 59: 831-836.

Wang X, Sun H, Xia Y, Chen C, Xu H, Shan H, Lu JR, 2009. Lysozyme mediated calcium carbonate mineralization. J. Colloid and Interface Science, 332: 96-103.

Xie AJ, Shen YH, Zhang CY, Yuan ZW, Zhu XM, Yang YM, 2005. Crystal growth of calcium carbonate with various morphologies in different amino acid systems. J. Crystal Growth, 285: 436-443.

Yu J, Lei M, Cheng B, Zhao X, 2004. Effects of PAA additive and temperature on morphology of calcium carbonate particles. J. Solid State Chemistry, 177: 681-689.

Zhang Z, Xie Y, Xu X, Pan H, Tang R, 2012. Transformation of amorphous calcium carbonate into aragonite. J. Crystal Growth, 343: 62-67.

Zhu Y, Liu Y, Ruan Q, Zeng Y, Xiao J, Liu Z, Cheng L, Xu F, Zhang L, 2009. Superstructures and mineralization of laminated vaterite mesocrystals via mesoscale transformation and selfassembly, J. Phys. Chem. C, 113: 6584-6588.

Wie H, Shen Q, Zhao Y, Wang DJ, Xu DF, 2003. Influence of polyvinylpyrrolidone on the precipitation of calcium carbonate and on the transformation of vaterite to calcite. J. Crystal Growth, 250:516-524. 